\title{
Anticoagulant and Preservative Solution for Blood Dosage Form
}

National Cancer Institute

\section{Source}

National Cancer Institute. Anticoagulant and Preservative Solution for Blood Dosage

Form. NCl Thesaurus. Code C149347.

Sterile aqueous liquid preparation intended to be mixed with extracorporeal blood to preserve the blood and prevent coagulation. 